\title{
Effect of blending ratio to the liquid product on co-pyrolysis of low rank coal and oil palm empty fruit bunch
}

\author{
Siti Zullaikah ${ }^{1, *}$, Ari Suryo Lenggono ${ }^{1}$, Dennis Farina Nury $^{1}$, and M. Rachimoellah ${ }^{1}$ \\ ${ }^{1}$ Chemical Engineering Department, Institut Teknologi Sepuluh Nopember, Kampus ITS, Keputih, Sukolilo, Surabaya 60111 \\ Indonesia
}

\begin{abstract}
The utilization of Indonesia low rank coal should be maximized, since the source of Indonesia law rank coals were abundant. Pyrolysis of this coal can produce liquid product which can be utilized as fuel and chemical feedstocks. The yield of liquid product is still low due to lower of comparison $\mathrm{H} / \mathrm{C}$. Since coal is non-renewable source, an effort of coal saving and to mitigate the production of greenhouse gases, biomass such as oil palm empty fruit bunch (EFB) would added as co-feeding. EFB could act as hydrogen donor in co-pyrolysis to increase liquid product. Co-pyrolysis of Indonesia low rank coal and EFB were studied in a drop tube reactor under the certain temperature $(T=$ $\left.500{ }^{\circ} \mathrm{C}\right)$ and time $(\mathrm{t}=1 \mathrm{~h})$ used $\mathrm{N}_{2}$ as purge gas. The effect of blending ratios of coal/EFB $(100 / 0,75 / 25,50 / 50,25 / 75$ and $0 / 100 \%$, w/w \%) on the yield and composition of liquid product were studied systematically. The results showed that the higher blending ratio, the yield of liquid product and gas obtained increased, while the char decreased. The highest yield of liquid product $(28,62 \%)$ was obtained used blending ratio of coal/EFB = $25 / 75$, w/w\%. Tar composition obtained in this ratio is phenol, polycyclic aromatic hydrocarbons, alkanes, acids, esters.
\end{abstract}

\section{Introduction}

Indonesia coal reserves in 2015 reached 126.61 billion tons, and about $80 \%$ of coal reserve was low rank coal. Lignite is a type of coal that is classified as low rank coal due to it has high water content and low caloric value[1]. The potential of coal resource in Indonesia is abundant, it's mainly distribute in South Sumatra, Central Java, Papua and Sulawesi[2]. Two conversion processes to convert coal into chemical products are biochemical and thermochemical processes. Biochemical conversion methods are based on the biological activity, whereas thermochemical process includes liquefaction, gasification, pyrolysis and combustion. Coal pyrolysis is a promising process to convert coal into liquid fuels and chemicals[3].

Products on thermochemical conversion are consist of volatile fraction, tar components and char rich of carbon residue. The pyrolysis process consists of a very complex reactions involving the formation of radicals. Pyrolysis is the most widely used to thermochemical processes which is the chemical decomposition of organic material by heating in the absence of oxygen[4].
Since the quantity and quality of pyrolysis products are limited because of the low atom ratio $\mathrm{H} / \mathrm{C}$ coal[5], so it needs a donor hydrogen from other resources, such as biomass. Biomass can act as donor hydrogen during pyrolysis. Biomass can also generate more liquid than gas product. In addition, biomass contains more volatile matter than coal.

Coal contains monocyclic and polycyclic aromatic structures that represent characteristics of its rank[6]. Coal conversion processes need to be developed further and needs to increased to modern requirements regarding rate of yield, purity and energetic aspects. A study gives an overview on the utilization of lignites for the production of value added chemicals[7]. Other study, which can be found in several of these conversion processes, is the pyrolysis of the higher molecular weight of coal feedstock into lower molecular weight products.

There are several studies focused on coal pyrolysis [7]. The liquids produced during pyrolysis are mixture that contains complex of organic compounds. Generally, the composition in organic compounds depend on the feedstock and pyrolysis conditions, from non-polar to polar and from low to high molecular weight compounds.

\footnotetext{
* Corresponding author: szulle@,chem-eng.its.ac.id, szullehakim@gmail.com
} 
Hydrogen from biomass can produced more volatiles compounds during co-pyrolysis than that produced from pyrolysis of each sample individually. Hydrogen can prevent recombination and cross-linking reactions during co-pyrolysis process[9]. The use of biomass as an energy source has been known to have environmentally benefits besides the abundance of its biomass. Biomass is considered to be a potential alternative energy source. Especially, biomass from agricultural and forestry industrial wastes that can be used for energy feedstocks.

Biomass is renewable energy resources and more environmentally friendly [8]. An interesting waste from oil palm mill is oil palm empty fruit bunch (EFB). EFB is by-product and one of the top ranked agricultural residues in Indonesia, the availability in Indonesia reaches 7,195,390 tons / year[10].

Several researcher have investigated the effect of blending ratio on pyrolysis products. A study on copyrolysis of biomass legume straw (LS) and lignite coal in a drop tube reactor from 500 to $700{ }^{\circ} \mathrm{C}$, the results shown a trend towards linear product distributions at higher temperatures. The results showed that the char yields decreased and consequently the liquid yields increased. The largest degree of synergetic effects on the products yields was observed under $600{ }^{\circ} \mathrm{C}$ and the blending ratio of $73 \mathrm{wt} . \%$ in the co-pyrolysis of LS/DY. It can be concluded that both the higher blending ratio (around $70 \mathrm{wt.} \%$ ) and the relatively lower temperature (around $600{ }^{\circ} \mathrm{C}$ ) are the best conditions during the copyrolysis of biomass and coal on free fall reactor[5], [7].

Study of biomass pyrolysis, such as rapeseed were conducted to determine the effect of pyrolysis, such as temperature, heating rate, particle size and gas flow rate on the pyrolysis product yields and their chemical compositions. The results of this experiment showed that the liquid yield product reached a higher of $68 \%$ by employing higher heating rate of $300{ }^{\circ} \mathrm{C}$ min-1 under temperature of $550{ }^{\circ} \mathrm{C}$ and particle size range of $0.6-$ $1.25 \mathrm{~mm}$. The proportion liquid products depends very much on the pyrolysis technique used and on the reaction parameters[11].

A research conducted to produce tar from Legume Straw (LS), Sawdust (SD), High-Rank (TF) and Low Rank Coal (DY). Liquid tar was produce more using High-Rank coal than that of Low Rank coal. The best conditions of the blending ratios are 50/50 and 70/30 at temperatures of $600^{\circ} \mathrm{C}$ and $700^{\circ} \mathrm{C}$, respectively. Liquid yields from co-pyrolysis of TF coal are higher than that of DY. Liquid product from the LS/DY co-pyrolysis was analyzed by means of solvent extraction-column chromatography combined with GC-MS. This is because coal levels also greatly spur liquid products from co-pyrolysis[7].

Other study on co-pyrolysis biomass and low rank coal, which produces more tar from low rank coals than pine wood. The best condition of the blending ratio is $70 \mathrm{wt} \%$ at temperature below $600{ }^{\circ} \mathrm{C}$. Hydrogen donor from biomass can produce more tar, this is because biomass contains higher volatile materials than coal[4], [1].
The effect blending ratio of co-pyrolysis on the product distributions was discussed in detail in this study. Identification of components in tar was done by gas chromatography/mass spectrometry (GC-MS).

\section{Experimental}

\subsection{Raw materials}

Low rank coal was obtained from PT. Semen Indonesia Persero (Tbk) and oil palm empty fruit bunch (EFB) was kindly supplied from oil palm plantation in Samarinda, East Kalimantan. The fresh EFB was chopped and dried by sunlight for 3 days before being grinded to reduce its particle size. Samples (coal and EFB) were dried in oven for 1 hour at $105^{\circ} \mathrm{C}$ and placed in dessicator for 30 minutes. Particle size of samples were distributed in a range of $0.71-1.19 \mathrm{~mm}$. The proximate and ultimate analyses of samples are shown in Table 1.

\subsection{Co-pyrolysis of low rank coal and EFB}

Co-pyrolysis was performed in a droptube reactor. It has length of $90 \mathrm{~cm}$, outside diameter of $2 \mathrm{inch}, 6 \mathrm{~mm}$ of thickness, and it made of stainless steel $216 \mathrm{H}$. Two thermocouples are inserted in the middle of reactor to measure the reactor temperature. Bend heater was installed on the reactor wall to heated up the reactor to the desired temperature. The reactor was heated up to $500^{\circ} \mathrm{C}$ at rate of $5^{\circ} \mathrm{C} / \mathrm{min}$ under constant $\mathrm{N}_{2}$ flow rate. A hopper was placed on the top of reactor to fed the sample (100g). Five blending ratios $(100 / 0,75 / 25$, $50 / 50,25 / 75$, and $0 / 100, \% \mathrm{w} / \mathrm{w}$ ) were employed in this study. Drop tube reactor used in this study was shown in fig. 1.

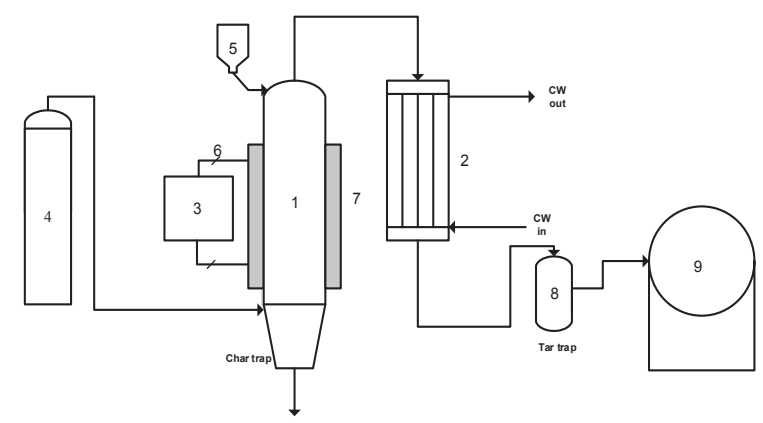

Fig. 1. Droptube reactor :

(1) reactor, (2) condenser, (3) controller, (4) $\mathrm{N}_{2}$ gas, (5) hopper,(6) thermocouple, (7) heater, (8) tar trap, (9) gas bag

The product gas was cooled through condenser to condensed a condensable gas (liquid product). The collected liquid was separated into tar and water by using a rotary evaporator at $60{ }^{\circ} \mathrm{C}$ under vacuum. Tar composition was analyzed qualitatively by using GCMS. Residual char left in the char trap was measured gravimatrically. The co-pyrolysis was carried out for 1 hour.

The samples were tested for ultimate analysis for 
carbon, hydrogen, nitrogen and sulphur contents. The proximate analysis was used to determine the moisture content, volatiles matter, ash content and fixed carbon in both coal and EFB. The HHV (higher heating value) were determined using a bomb calorimeter PARR 1261. TGA (Thermogravimetric analysis) was carried out on the sample of size $\sim 10 \mathrm{mg}$ in order to evaluate the qualitative composition of sample, in particular thermal degradation behavior. TGA was performed with heating rate of $10{ }^{\circ} \mathrm{C} / \mathrm{min}$, heated from $25{ }^{\circ} \mathrm{C}-900{ }^{\circ} \mathrm{C}$ under $\mathrm{N}_{2}$ gas flow. Schematic diagram is shown in Fig $\mathbf{1 .}$

\section{Results and discussion}

The product yields from the co-pyrolysis of low rank coal and EFB at different blending ratios and yield of tar at temperature $500^{\circ} \mathrm{C}$ are given in Fig.3 and 4, The product yields are calculated by :

$$
\begin{aligned}
& \text { Yield of char }=\frac{\text { Char product }(g)}{\text { Sample }(g)} \times 100 \% \\
& \text { Yield of liquid }=\frac{\text { Liquid product }(g)}{\text { Sample }(g)} \times 100 \% \\
& \text { Yield of gas }=\frac{\text { Gas product } 9 \mathrm{~g})}{\text { Sample }(\mathrm{g})} \times 100 \% \\
& \text { Yield of tar }=\frac{\text { Tar product }(\mathrm{g})}{\text { Sample } 9 \mathrm{~g})} \times 100 \%
\end{aligned}
$$

The proximate analysis is analyzed according to ASTM D 5142. Ultimate analysis was performed to determine elemental composition by ASTM D-5373 and ASTM D-4239 to determine of total sulfur.

As shown in Table $1, \mathrm{H} / \mathrm{C}$ ratio of EFB is higher than that of coal. It has been reported previously that more volatiles can be produced from coal pyrolysis by adding hydrogen-donorsfrom other organic resources, such as biomass.Higher content of $\mathrm{H}_{2}$ in EFB may be used as $\mathrm{H}_{2}$-donor during co-pyrolysis with coal [5].

Table 1 Proximate and Ultimate analysis of samples

\begin{tabular}{|l|c|c|}
\hline \multirow{2}{*}{ Parameter } & \multicolumn{2}{|c|}{ Sample } \\
\cline { 2 - 3 } & Coal & EFB \\
\hline Proximate analysis & & \\
\% Moisture content & 20.51 & 7.13 \\
\% Fixed carbon & 38.50 & 29.00 \\
\% Ash content & 5.00 & 12.00 \\
\% Volatile matter & 60.00 & 76.00 \\
Ultimate Analysis & & \\
\% Carbon & 54.70 & 42.65 \\
\% Hydrogen & 5.83 & 6.45 \\
\% Nitrogen & 0.75 & 0.61 \\
\% Sulphur & 0.24 & 0.19 \\
\% Oxygen & 38.48 & 50.10 \\
H/C & 1.28 & 1.82 \\
HHV (MJ/kg) & 26.00 & 14.50 \\
\hline
\end{tabular}

\subsection{Effects of blending ratio on product yields}

Fig 2 shown a thermogravimetric (TG) of coal/EFB at any blending ratios. At the blending ratio of coal: $\mathrm{EFB}=$
$25 / 75$ and $50 / 50$ are quite similar to $100 \%$ EFB. At the blending ratio of coal: EFB $75 / 25$ was similar to that of using coal $100 \%$. From TG profile, it seen that blending ratio of $25-100 \%$ EFB is more active than coal alone.

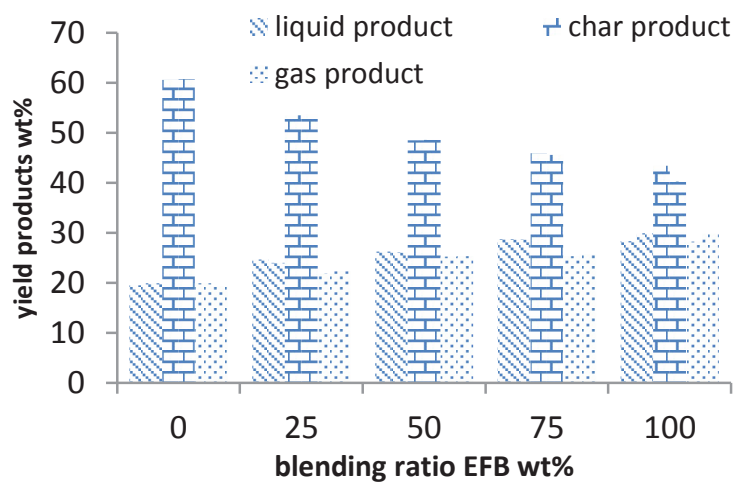

Fig.2. TG of coal/EFB at any blending ratios

Coal decomposition temperature ranges (329.13 $\left.687{ }^{\circ} \mathrm{C}\right)$, EFB $\left(259.61-362{ }^{\circ} \mathrm{C}\right)$, Coal: EFB 25/75 (259.63-315 $\left.{ }^{\circ} \mathrm{C}\right)$, Coal: EFB 50/50 $\left(261,18-360{ }^{\circ} \mathrm{C}\right)$ and Coal: EFB 75/25 (246.43-362 $\left.{ }^{\circ} \mathrm{C}\right)$.

The comparison with the result of TGA conducted [12] on co-pyrolysis subbituminous coal with Malaysia EFB on blending ratioof EFB / Coal 0,20,40,50,60, 80, and $100 \%$ for temperature range of $25-900{ }^{\circ} \mathrm{C}$ were obtained two DTG peaks with each T1 $=300-301{ }^{\circ} \mathrm{C}$ and $\mathrm{T}_{2}=425-433{ }^{\circ} \mathrm{C}$. TGA results in this study have lower decomposition temperature range.

The gas, liquid and char product yields co-pyrolysis of coal/EFB was shown in Fig 3. The results of both coal and EFB have the same trend in the acquisition of gas, liquid and char product yields. Increasind of blending ratio, the yield of liquid and gas increased while the yield of char decreased.

The general products trend shows that the amount of gas and liquid products increased, while the char products decreased with blending ratio of coal/EFB. Those results consistent with the previous study on copyrolysis of legume straw and lignite in a drop tube reactor from 500 to $700{ }^{\circ} \mathrm{C}$. There was a trend towards linear product distributions at higher temperatures [5]. At the higher blending ratio, hydrogen availability during pyrolysis is much greater. Hydrogen in EFB can be used as hydrogen donor during co- pyrolysis.

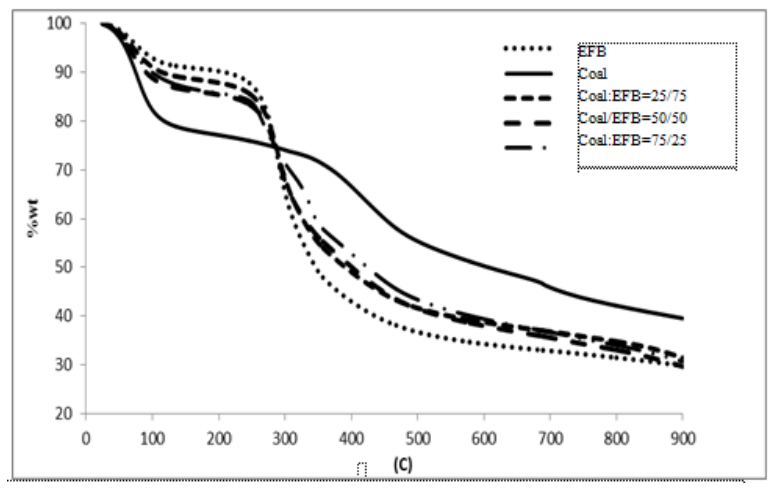

Fig.3. Product yields of coal/EFB at any blending ratio 
Hydrogen from biomass may prevent recombination and cross-linking reactions of free radicals that increase char formation [5].

The liquid yield of EFB is greater than that of coal, this can be seen on individual variables, 100/0 and 0/100 respectively. This is because EFB has higher volatile matter than coal which can be seen from proximate analysis in Table 1.

\subsection{Physical and chemical properties of liquid product}

The liquid product was separated into two phases, tar and water by using a rotary evaporator at $60{ }^{\circ} \mathrm{C}$ under vacuum. The yields are given in Fig 4. At individual sample, coal $/ \mathrm{EFB}=100 / 0 \mathrm{wt} \%$ and coal $/ \mathrm{EFB}=0 / 100$ wt $\%$, the yield of tar were $1.96 \%$ and $6.84 \%$, respectively. The yield of tar at blending ratio of $25 \mathrm{wt} \%$ to $75 \mathrm{wt} \%$ EFB were increased. The maximum yield of tar $(9.05 \%)$ was obtained under the condition of blending ratio of $75 \mathrm{wt} \%$.

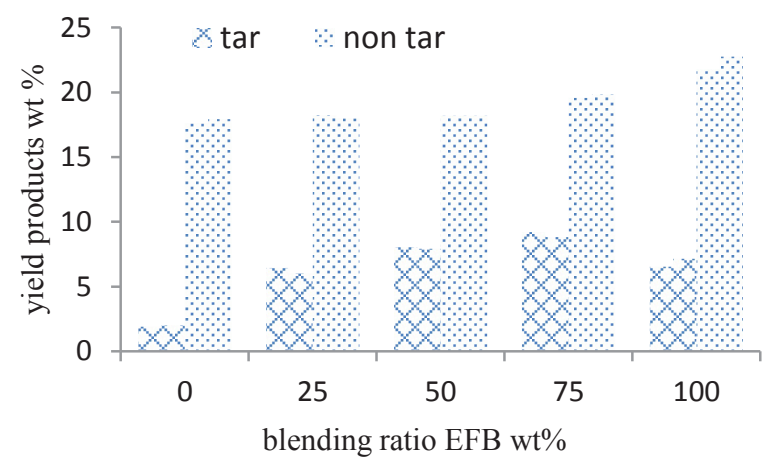

Fig.4. Liquid product yield of coal/EFB at any blending ratio

\subsection{Identification of Liquid Compounds by Using GC MS analysis}

The liquid product contains an organic phase and a high water content of the aqueous phase. The addition of polar solvents such as methanol or ethanol represents one of the easiest routes [13] and it was estabilished by the authors of this research that the two phases both readily dissolved in methanol giving a homogeneous single phase product with a low viscosity.

(a)

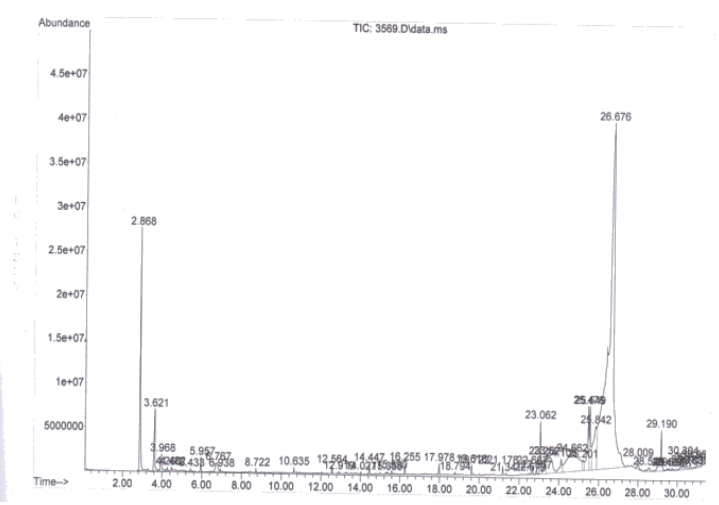

(b)

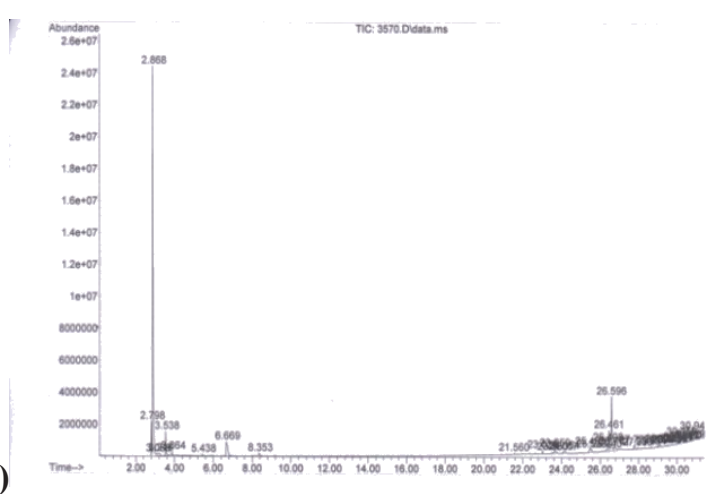

(c)

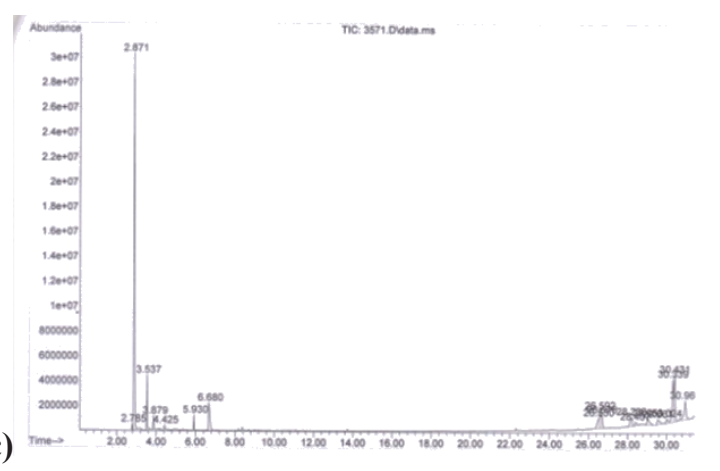

(d)

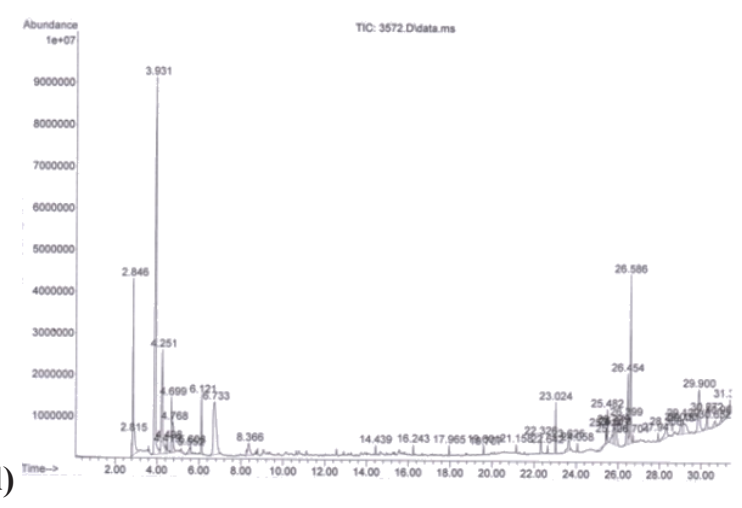

(e)

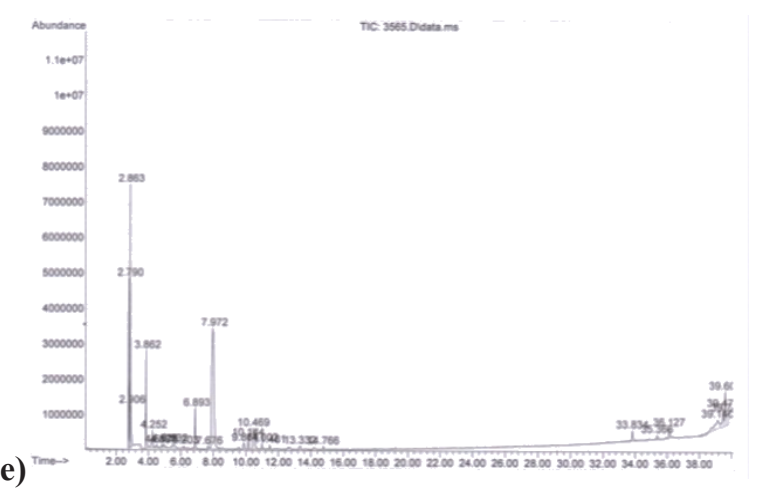

Fig 5. GC MS of liquid products at any blending ratios. (a) EFB $0 \mathrm{wt} \%$; (b) EFB $25 \mathrm{wt} \%$; (c) EFB $50 \mathrm{wt} \%$; (d)EFB 75 wt $\%$; (e) EFB $100 \mathrm{wt} \%$

Tar is consist of many compounds dissolved water. From fig. 5 (a) to (e), we can classified that tar is mainly consist of phenolic compound, acid and ester, alkanes and PAHs (polycyclic aromatic hydrocabons).

The aqueous phase could potentially be co-fired to reduce thermal NOx and enable efficient burning of its dissolved dry matter. As mentioned in the introduction, 
it might also be possible to obtain phenolic compounds for resin making, as a commercial by-product.

Thermochemical upgrading is another possibility, either via gasification and Fischer-Tropsch, where it may be advantageous to gasify a bio-oil char slurry rather than the biomass. The organic phase may also be used directly in engines, turbines and boilers, if it is first pre-heated to reduce its viscosity, though its thermal instability might limit the temperature it can be brought up to[6], [11].

At blending ratio of $\mathrm{EFB} 75 \mathrm{wt} \%$, tehre are compounds tetradecanoic acid, methyl ester which is the compiler of biodiesel and eicosanol which is an alcohol compound.

In addition, alkanes, alkenes and esters, phenols, benzene, aldehydes, ketones and PAHs were also found at each blending ratio. Percentage of phenols, PAHs decreased, but acid levels increased respectively.

The tar products identified by GC MS analysis, can be utilized in their respective applications. Alkanes compounds can be used as based oil. The compound of acid and ester can be used as feedstuffs for various agnets of food and beverages, textiles, plastic lubricants, paints and its additive, surfactants and pharmaceuticals. Also methyl ester compound which is a biodiesel constituent. PAHs such as naphtalens may be used as an additive.

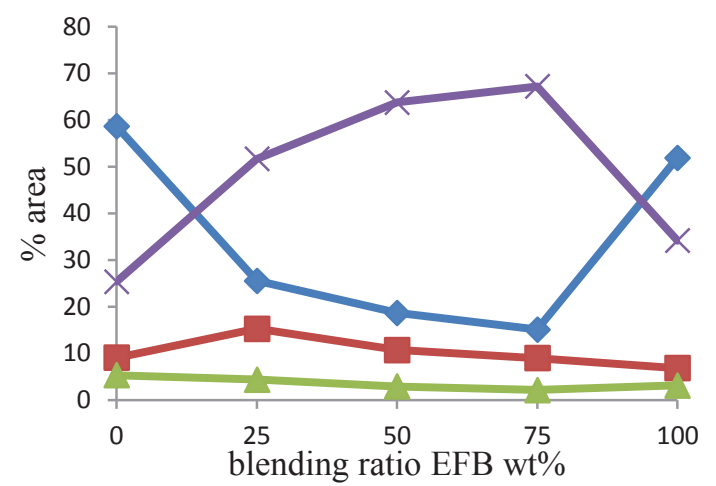

Fig.6 Distributions of liquid product at any blending ratio

Distribution the abundances of the liquid product given in Fig.6. Based on GC MS result for EFB 0wt\%, the maximum percentage of area are phenols, alkanes and PAHs. This result is accordance which states that liquid coal contains phenolic compounds and polycyclic aromatic hydrocarbons (PAHs) [14].

GC MS analysis results for EFB $100 \mathrm{wt} \%$, have found alkanes, acid and ester, phenol and PAHs. Similarly, experiment on pyrolysis of pomegranate seed contains alkanes, phenols, acids, esters and polycyclic aromatic hydrocarbons (PAHs) on liquid products [9].

However, GC MS analysis results for EFB $25 \mathrm{wt} \%$ up to $75 \mathrm{wt} \%$ blending ratio, the percentage of phenols, alkanes, polycyclic aromatic hydrocarbons (PAHs) decreased, but the acid and ester increased respectively.

\section{Conclusions}

Co-pyrolysis of coal with biomass was performed in a droptube reactor working at constant pressure $\mathrm{N}_{2}$ gas, under operation conditions of temperature of $500^{\circ} \mathrm{C}$ and 1 hour. The results showed that the higher blending ratio, the yield of liquid product and gas obtained increased, while the char decreased. The highest yield of liquid product $(28.62 \%)$ was obtained used blending ratio of coal/ $/ \mathrm{EFB}=25 / 75$. Tar composition obtained in this ratio is phenol, polycyclic aromatic hydrocarbons, alkanes, acids, esters. From GC MS analysis, there are found phenol, alkanes, acid and esters, polycyclic aromatic hydrocarbons (PAHs).Methyl ester was also found, a type of fatty acid ester that are derived by transesterification of fats with methanol. The molecules are primarily methyl ester, used to produce biodiesel. It can be concluded from this study that co-pyrolysis of low rank coal and EFB, which has a positive effect on liquid product.

The authors would like to express their gratitude to the RISTEKDIKTI on Program Kreativitas Mahasiswa (PKM) for funding this research with grant number: 547/B3.1/KM/2017. The authors would like to thank all members of Biomass Laboratory for their valuable help during this research work. The authors also thank to Chemical Engineering Department Institut Teknologi Sepuluh Nopember (ITS)for the valuable help and support during this research.

\section{References}

1. R. M. Soncini, N. C. Means, and N. T. Weiland, Fuel, 112, 74-82, (2013).

2. D. Supramono, and S. Lusiani, IOP Conf. Ser.: Mater. Sci. Eng., 162 (1), 1-14, (2017).

3. S. Yaman, Chem. In. Form., 35 (5), 651-671, (2004).

4. N. T. Weiland, N. C. Means, and B. D. Morreale, Fuel, 94, 563-570 (2012).

5. L. Zhang, S. Xu, W. Zhao, and S. Liu, Fuel, 86 (3), 353-359 (2007).

6. O. Onay, E. Bayram, and O. M. Kockar, Energy Fuel, 21 (5) 3049-3056, (2007).

7. W. E. I. Li-gang, Z. Li, and X. U. Shao-ping, J. Fuel Chem. Technol., 39 (10) 728-734, (2011).

8. D. Mohan, C. U. Pittman, and P. H. Steele, Energy Fuel, 20 (3), 848-889 (2006).

9. S. Uçar and S. Karagöz, J. Anal. Appl. Pyrolysis, 84 (2) 151-156, (2009).

10. S. N. Sholikhah, V. S. Bonavia, K. Pertanian, and R. Indonesia,

11. O. Onay and O. M. Kockar, Ren. Energy, 28 (15), 2417-2433, (2003).

12. F. Sulaiman and N. Abdullah, Energy, 36 (5) 2352 2359 (2011).

13. S. Krerkkaiwan, C. Fushimi, A. Tsutsumi, and P. Kuchonthara, Fuel Process. Technol., 115, 11-18 (2013)

14. N. Abdullah and H. Gerhauser, Fuel, 87, 2606-2613 (2008). 